\title{
Orofaciodigital syndrome type 14
}

INSERM

\section{Source}

INSERM. (1999). Orphanet: an online rare disease and orphan drug data base.

Orofaciodigital syndrome type 14. ORPHA:434179

Orofaciodigital syndrome type 14 is a rare subtype of orofaciodigital syndrome, with autosomal recessive inheritance and C2CD3 mutations, characterized by severe microcephaly, trigonocephaly, severe intellectual disability and micropenis, in addition to oral, facial and digital malformations (ging ival frenulae, lingual hamartomas, cleft/lobulated tongue, cleft palate, telecanthus, up-slanting palpebral fissures, microretrognathia, postaxial polydactyly of hands and duplication of hallux). Corpus callosum agenesis and vermis hypoplasia with molar tooth sign, on brain imaging, are also associated. 